\title{
PRODUCTIVITY AND PROFITABILITY OF INTERCROPPING SESAME WITH TURMERIC AT MARGINAL FARMERS LEVEL OF BANGLADESH
}

\author{
M. R. Islam ${ }^{\text {** }}$ M. S. H. Molla ${ }^{2}$ and M. A. K. Main ${ }^{3}$ \\ ${ }^{1}$ Agronomy Division, Regional Agricultural Research Station, BARI \\ Ishwardi, Pabna, Bangladesh \\ ${ }^{2}$ On Farm Research Division, BARI, Pabna, Bangladesh \\ ${ }^{3}$ Regional Agricultural Research Station, BARI, Ishwardi, Pabna, Bangladesh
}

\begin{abstract}
Turmeric-sesame intercrops at different planting densities were studied at the Regional Agricultural Research Station, Ishwardi, Pabna, Bangladesh in 2014 and 2015 to find out the productivity and economic performance of intercropping sesame with turmeric. The experiment was laid out in RCB design maintaining three replication with five treatments viz., turmeric $(100 \%)+1$ row sesame $(33 \%)$ in between turmeric lines, turmeric $(100 \%)+2$ row sesame $(67 \%)$ in between turmeric lines, turmeric $(100 \%)+3$ row sesame $(100 \%)$ in between turmeric lines, turmeric $(100 \%)+$ sesame broadcast $(100 \%)$ in between turmeric lines, sole turmeric and sole sesame. Rhizome yield of turmeric was significantly higher in all intercropping systems $\left(22.85-23.77 \mathrm{t} \mathrm{ha}^{-1}\right)$ than in monoculture system $\left(18.00 \mathrm{t} \mathrm{ha}^{-1}\right)$. The maximum turmeric yield $(23.77$ $\left.\mathrm{t} \mathrm{ha}^{-1}\right)$ was obtained from turmeric $(100 \%)+3$ row sesame $(100 \%)$ in between turmeric lines intercropping system, which was also exhibited higher turmeric equivalent yield $\left(26.05 \mathrm{t} \mathrm{ha}^{-1}\right)$, benefit cost ratio (3.50), land equivalent ratio (2.28), competitive indices values, SPI (41.09) and MAI (Tk. $294952.62 \mathrm{ha}^{-1}$ ) compared to the other intercropping and sole cropping system.
\end{abstract}

Keywords: Economic, intercropping, turmeric, sesame

\section{INTRODUCTION}

Bangladesh is an agriculture based country and about $16.33 \%$ of the gross domestic product (GDP) comes from agriculture (AIS, 2015). Majority of the farmers are marginal and their land size is averagely from 0.05 to 2.49 acres (MOA, 2014). Beside of this, the cultivable land area is decreasing day by day with the increasing of human population and subsequently urbanization and industrialization in Bangladesh.

\footnotetext{
* Corresponding author email: rafiq_bari2@yahoo.com
}

Received: 23.02.2016 
Increasing food demand for the over population is creating challenge to the country for increasing productivity of the limited land. The cultivation of sesame is drastically declining due to widely increasing of rice, maize and mungbean cultivation in kharif- 1 season. Moreover, sesame competes with jute and different vegetables in the season. Now cultivation of long duration crops are discouraged and simultaneously short duration crops, mixed crop and intercrops are emphasized for cultivation to ensure food security for a large number of population. Intercropping system is a production method with more than one crop together to increase the productivity. Consequently, intercropping is a time demanding technology for cultivation of long duration crops. So, intercropping of sesame with turmeric will help to retain oilseed and spices crops in existing cropping pattern. It will also play an important role to ensure highest productivity per unit area as well as supply oil in our food menu. It is mentioned that about 35-47 $\mathrm{g}$ oil/fat is required for a adult person per day but we consume only 17-19 g per day, which is half of the full requirement (Ullah et al., 2001). At present, the domestic production of edible oil can only meet about $20 \%$ of the country annual demand and rest is imported which costs more than Tk. 20 billion (BSA, 2013). Moreover, many children in our country severely suffer in blindness which occurred due to deficiency of Vitamin A. It is soluble in oil only. So, if we include substantial amount of oil in our daily food list that will play a vital role to decrease blindness. Turmeric is a long durated (270-290 days) wide spaced $(50-60 \mathrm{~cm})$ crop that is required 60-70 days for $100 \%$ emergences. It can be cultivated in shady places as they are partially shade loving crops (Haque and Hossain, 1985 and Joyachandran et al., 1991). So, farmers can easily grow a short duration crop as intercrop with turmeric at early growth stage. Sesame is a short durated (90-95 days) crop and it is grown in same cropping seasons of turmeric. However, sesame may be grown as intercrop as they have different growth habit, growth duration and demand for growth resources. The farmers usually grow turmeric as a sole crop in the open sunny place. Joyachandran et al. (1991) reported from India that higher fresh turmeric yield was obtained in intercropping situation than sole crop due to shady condition than those in open sunlight. With this view, the present experiment was undertaken to find out the productivity and profitability of intercropping sesame with turmeric.

\section{MATERIALS AND METHODS}

The experiment was conducted at the Regional Agricultural Research Station, Ishwardi, Pabna, Bangladesh during 2014 and 2015 to find out the productivity and economic performance of intercropping sesame with turmeric. Treatments were viz. $\mathrm{T}_{1}=$ Turmeric $(100 \%)+1$ row sesame $(33 \%)$ in between turmeric lines, $\mathrm{T}_{2}$ $=$ Turmeric $(100 \%)+2$ row sesame $(67 \%)$ in between turmeric lines, $\mathrm{T}_{3}=$ Turmeric $(100 \%)+3$ row sesame $(100 \%)$ in between turmeric lines, $\mathrm{T}_{4}=$ Turmeric $(100 \%)+$ sesame broadcast $(100 \%)$ in between turmeric lines, $\mathrm{T}_{5}=$ Sole turmeric and $\mathrm{T}_{6}=$ Sole sesame. The experiment was laid out in a randomized complete block design with 
three replications. The unit plot size was $4.5 \mathrm{~m} \times 4 \mathrm{~m}$. Turmeric was the main crop and sesame was the intercrop in the study. Sesame was intercropped in between turmeric row @ 33\%,67\% and 100\% population. The turmeric variety BARI Halud-4 and sesame variety BARI Til-4 were planted/sown on 22 March 2014 and 20 March 2015, respectively. Except broadcasting, sesame seeds were sown in line $(30 \mathrm{~cm}$ apart row) following continuous seeding and finally maintained about $5 \mathrm{~cm}$ plant to plant distance by thining. The sole crop of turmeric and intercrops were fertilized with 140-54-117 $\mathrm{kg} \mathrm{ha}^{-1}$ of $\mathrm{N}, \mathrm{P}, \mathrm{K}$ respectively with $5 \mathrm{t} \mathrm{ha}^{-1}$ cowdung where $1 /{ }_{3} \mathrm{~N}$ and $1 / 2$ of $\mathrm{K}$ and other fertilizers were used as basal. Rest of $\mathrm{N}$ was applied in three equal splits at 30, 95 and 120 days after planting (DAP)/DAS. Remaining K was applied at 95 and 120 DAP. Sole crop of sesame was fertilized with 60-30-25-20-2-2 $\mathrm{kg} \mathrm{ha}^{-1}$ of N-P-K-S-Zn-B respectively, where $1 / 2 \mathrm{~N}$ and all other fertilizers were applied as basal. Rest $\mathrm{N}$ was top dressed at 30 DAS. Weeding and other intercultural operations were done as and when necessary. Earthing up for turmeric was done after harvesting of sesame. Turmeric was harvested on 31 December 2014 and 28 December 2015, respectively. Sesame was harvested on 26 June 2014 and 30 June 2015 , respectively. Data on yield and yield attributes were collected and analyzed statistically. The mean values were adjudged by LSD (0.05) test. Turmeric equivalent yield (TEY) was calculated as per following formula:

$\mathrm{TEY}=$ Yield of intercrop turmeric $+\frac{\mathrm{Yi} \times \mathrm{Pi}}{\text { Price of turmeric }}$

Where, $\mathrm{Yi}=$ yield of intercrops and $\mathrm{Pi}=$ Price of intercrop .

The relative advantage of intercropping compared to sole culture was calculated for each proportion on a plot basis using the total land equivalent ratio (LER):

$\mathrm{LER}=\mathrm{RY}_{\mathrm{t}}+\mathrm{RY}_{\mathrm{i}}=\frac{\mathrm{T}_{\mathrm{IY}}}{\mathrm{T}_{\mathrm{SY}}}+\frac{\mathrm{S}_{\mathrm{IY}}}{\mathrm{S}_{\mathrm{SY}}}$

Where,

$\mathrm{RY}_{\mathrm{t}}=$ Relative yield of turmeric (main crop), $\mathrm{RY} \mathrm{Y}_{\mathrm{i}}=$ Relative yield of intercrops (sesame), $\mathrm{T}_{\mathrm{IY}}=$ Intercrop yield of turmeric, $\mathrm{T}_{\mathrm{SY}}=$ Sole crop yield of turmeric, $\mathrm{S}_{\mathrm{IY}}=$ Intercrop yield of sesame, $S_{\mathrm{SY}}=$ Sole crop yield of sesame

Replacement value of intercropping (RVI) and monetary advantage index (MAI) was calculated according to Moseley (1994) and Ali and Mishra (1993), respectively:

$\mathrm{RVI}=\frac{\mathrm{aP}_{1}+\mathrm{bP}_{2}}{\mathrm{aM}_{1}-\mathrm{C}}$

Where,

$\mathrm{P}_{1} \& \mathrm{P}_{2}$ are the yield of intercrops and $\mathrm{a} \& \mathrm{~b}$ are the respective prices of these crops. $\mathrm{M}_{1}$ is the yield and $\mathrm{C}$ is the input cost the primary (main) crop in sole stand. 
The monetary advantage index (MAI) was calculated as described by Gosh (2004).

MAI $=$ Value of combined intercrop yield $\times($ LER-1)/LER

Where,

MAI $=$ Monetary advantage index, $\mathrm{LER}=$ Land equivalent ratio

The competitive ratio (CR) among different combinations was calculated using the following formula (Willey, 1980):

Competitive ratio $=\frac{\text { LER of } \operatorname{crop}(\mathrm{a})}{\text { LER of } \operatorname{crop}(\mathrm{b})}$

The relative crowding coefficient $(\mathrm{k})$ and aggressivity $(\mathrm{A})$ were determined based on Willey and Rao (1980) using mean grain yield values of treatments averaged across years and replications as follows:

$\mathrm{K}=\mathrm{kab} \times \mathrm{kba}=\left[\frac{\mathrm{Y}_{\mathrm{ab}} \times \mathrm{Z}_{\mathrm{ba}}}{\left(\mathrm{Y}_{\mathrm{aa}}-\mathrm{Y}_{\mathrm{ab}}\right) \times \mathrm{Z}_{\mathrm{ab}}}\right] \times\left[\frac{\mathrm{Y}_{\mathrm{ba}} \times \mathrm{Z}_{\mathrm{ab}}}{\left(\mathrm{Y}_{\mathrm{bb}}-\mathrm{Y}_{\mathrm{ba}}\right) \times \mathrm{Z}_{\mathrm{ba}}}\right]$

Aggressivity of turmeric $(A a b)=\frac{Y_{a b}}{Y_{a a} \times Z_{a b}}-\frac{Y_{b a}}{Y_{b b} \times Z_{b a}}$

Aggressivity of sesame $(\mathrm{Aba})=\frac{\mathrm{Y}_{\mathrm{ba}}}{\mathrm{Y}_{\mathrm{bb}} \times \mathrm{Z}_{\mathrm{ba}}}-\frac{\mathrm{Y}_{\mathrm{ab}}}{\mathrm{Y}_{\mathrm{aa}} \times \mathrm{Z}_{\mathrm{ab}}}$

Where,

$\mathrm{Kab}$ and Kba are relative crowding coefficient for turmeric and sesame. $\mathrm{Y}_{\mathrm{ab}}=$ Intercropped yield of turmeric, $Y_{b a}=$ Intercropped yield of sesame, $Y_{a a}=$ Sole crop yield of turmeric, $Y_{b b}=$ Sole crop yield of sesame, $Z_{a b}=$ Sown proportion of turmeric, $\mathrm{Z}_{\mathrm{ba}}=$ Sown proportion of sesame

The system productivity index (SPI) was calculated based on Odo (1991):

System productivity index $(\mathrm{SPI})=\frac{\mathrm{S}_{\mathrm{a}}}{\mathrm{S}_{\mathrm{b}}} \mathrm{Y}_{\mathrm{b}}+\mathrm{Y}_{\mathrm{a}}$

Where,

$S_{a}=$ Mean yield of turmeric in sole culture, $S_{b}=$ Mean yield of sesame in sole culture, $\mathrm{Y}_{\mathrm{a}}=$ Mean yield of turmeric in mixed culture, $\mathrm{Y}_{\mathrm{b}}=$ Mean yield of sesame in mixed culture 


\section{RESULTS AND DISCUSSION}

\section{Yield and yield attributes of turmeric}

The yield and yield contributing characters of turmeric was significantly different due to intercropping of sesame (Table 1). All the values of yield contributing characters were given highest under turmeric $(100 \%)+3$ row sesame $(100 \%)$ in between turmeric lines intercropping system compared to other intercropping system and sole cropping. Regarding the data, it was found that rhizome yield of turmeric was significantly higher in intercropping (22.85-23.77 tha $\left.{ }^{1}\right)$ than in monoculture system $\left(18.80 \mathrm{t} \mathrm{ha}^{-1}\right)$ with the maximum value $\left(23.77 \mathrm{t} \mathrm{ha}^{-1}\right)$ under turmeric $(100 \%)+3$ row sesame $(100 \%)$ in between turmeric lines intercropping system. Sole crop of turmeric fail to produce higher rhizome yield compared to intercropping system. It might be due to at open sunlight (sole turmeric) the growth and development was poorer than intercropped condition. Moreover, the emergence of turmeric plants was faster in sesame-turmeric intercropping system than sole turmeric. That's why it's lead the better growth and development as well as rhizome yield in sesame-turmeric intercropping situation compared to sole turmeric. The results confirm the findings of Joyachandran et al. (1991) who reported that higher fresh turmeric yield was obtained in intercropping situation than sole crop due to shady condition than those in open sunlight. The rhizome yield increased 4 to $32 \%$ in intercropping situation than sole crop of turmeric.

\section{Yield contributing characters and yield of sesame}

The considerable variation was found in case of branches/plant, capsules/plant and seed yield/ha while plant height, seeds/capsule and 1000-seed weight were not significant (Table 2). The maximum number of branches/plant (5.09) was recorded in turmeric $100 \%+1$ line sesame $(33 \%)$ in between two turmeric lines followed by turmeric $100 \%+2$ line sesame $(33 \%)$ in between two turmeric lines intercropping system. The lowest number of branches/plant (3.82) was observed in turmeric $100 \%$ + sesame broadcast (100\%) in between two turmeric lines combination. Increase in sesame population with turmeric decreased the number of branches/plant. The maximum number of capsules/plant (90.92) was recorded from the turmeric $100 \%+$ 1 line sesame (33\%) in between two turmeric lines. Reduction in number of capsules/plant was found with increased plant population of sesame. Higher number of capsules/plant in the combination of lower population of sesame might be due to production of more branches in sesame plants as compared to the combination with dense population. 
Table 1. Yield and yield contributing characters of turmeric (pooled average of 2014 and 2015)

\begin{tabular}{c|c|c|c|c|c|c|c}
\hline Treatments & $\begin{array}{c}\text { Plant } \\
\text { height } \\
(\mathrm{cm})\end{array}$ & $\begin{array}{r}\text { Uumber o } \\
\text { mother } \\
\text { rhizome/ } \\
\text { lant }\end{array}$ & $\begin{array}{c}\text { Numbe } \\
\text { of } \\
\text { fingers/p) } \\
\text { ant } \\
(\mathrm{No})\end{array}$ & $\begin{array}{c}\text { Weight of } \\
\text { mother } \\
\text { rhizome/plan } \\
(\mathrm{g})\end{array}$ & $\begin{array}{c}\text { Weight of } \\
\text { fingers/plant } \\
(\mathrm{g})\end{array}$ & $\begin{array}{c}\text { Rhizome } \\
\text { yield } \\
(\mathrm{t} / \mathrm{ha})\end{array}$ & $\begin{array}{c}\text { Rhizome } \\
\text { yield } \\
\text { increased } \\
(\%) \text { over } \\
\text { sole } \\
\text { turmeric }\end{array}$ \\
\hline $\mathrm{T}_{1}$ & 121.63 & 6.76 & 17.18 & 217.77 & 359.75 & 18.80 & 4 \\
$\mathrm{~T}_{2}$ & 123.73 & 7.86 & 18.22 & 237.17 & 379.25 & 22.85 & 27 \\
$\mathrm{~T}_{3}$ & 125.06 & 8.08 & 19.13 & 238.90 & 418.41 & 23.77 & 32 \\
$\mathrm{~T}_{4}$ & 123.10 & 7.90 & 18.74 & 224.99 & 419.77 & 23.72 & 32 \\
$\mathrm{~T}_{5}$ & 120.37 & 5.95 & 16.43 & 179.33 & 355.21 & 18.00 & - \\
\hline $\mathrm{LSD}(0.05)$ & $\mathrm{NS}$ & 0.55 & 1.03 & 16.73 & 26.75 & 1.34 & - \\
$\mathrm{CV}(\%)$ & 3.24 & 6.13 & 4.70 & 6.22 & 5.66 & 5.10 & - \\
\hline
\end{tabular}

Table 2. Yield contributing characters and yield of sesame (pooled average of 2014 and 2015)

\begin{tabular}{c|c|c|c|c|c|c|c}
\hline Treatments & $\begin{array}{c}\text { Plant } \\
\text { height } \\
(\mathrm{cm})\end{array}$ & $\begin{array}{c}\text { Branches/Fapsules/p } \\
\text { plant (no.) }\end{array}$ & $\begin{array}{c}\text { Seeds/ } \\
\text { lant } \\
\text { (no.) }\end{array}$ & $\begin{array}{c}\text { 1000-seed } \\
\text { (no.) }\end{array}$ & Yield (t/ha) & $\begin{array}{c}\text { Yield decreased (\%) } \\
\text { over sole sesame }\end{array}$ \\
\hline $\mathrm{T}_{1}$ & 119.90 & 5.09 & 90.92 & 59.95 & 3.27 & 0.62 & 53 \\
$\mathrm{~T}_{2}$ & 118.11 & 4.47 & 87.96 & 59.04 & 3.19 & 1.13 & 14 \\
$\mathrm{~T}_{3}$ & 117.34 & 4.36 & 84.06 & 58.34 & 3.15 & 1.27 & 4 \\
$\mathrm{~T}_{4}$ & 116.28 & 3.82 & 60.08 & 57.20 & 2.92 & 1.22 & 8 \\
$\mathrm{~T}_{6}$ & 116.75 & 4.39 & 74.14 & 58.37 & 3.16 & 1.32 & - \\
\hline $\mathrm{LSD}_{(0.05)}$ & $\mathrm{NS}$ & 0.18 & 4.24 & $\mathrm{NS}$ & $\mathrm{NS}$ & 0.09 & - \\
$\mathrm{CV}_{(\%)}$ & 4.69 & 3.30 & 4.36 & 2.90 & 6.96 & 6.65 & - \\
\hline
\end{tabular}

$\mathrm{T}_{1}=$ Turmeric $(100 \%)+1$ row sesame $(33 \%)$ in between turmeric lines, $\mathrm{T}_{2}=$ Turmeric $(100 \%)+2$ row sesame $(67 \%)$ in between turmeric lines, $\mathrm{T}_{3}=$ Turmeric $(100 \%)+3$ row sesame $(100 \%)$ in between turmeric lines, $\mathrm{T}_{4}=$ Turmeric $(100 \%)+$ sesame broadcast $(100 \%)$ in between turmeric lines, $\mathrm{T}_{5}=$ Sole turmeric and $\mathrm{T}_{6}=$ Sole sesame 
The highest seed yield of sesame (1.32) was recorded from the sole sesame. In the intercrops, the maximum seed yield $\left(1.27 \mathrm{t} \mathrm{ha}^{-1}\right)$ was found in turmeric $100 \%+3$ lines sesame $(100 \%)$ in between two turmeric lines followed by turmeric $100 \%+$ sesame broadcast $(100 \%)$ in between two turmeric lines combination. The lowest seed yield $\left(0.62 \mathrm{t} \mathrm{ha}^{-1}\right)$ was recorded in turmeric $100 \%+1$ line sesame $(33 \%)$ in between two turmeric lines combination because of the lowest plant population of sesame in per unit area. Sesame gave 4 to 53 percent higher yield in monoculture as compared to their corresponding intercropped yield. The crop performance in different stages of turmeric - sesame intercropping systems was shown in figure 1.

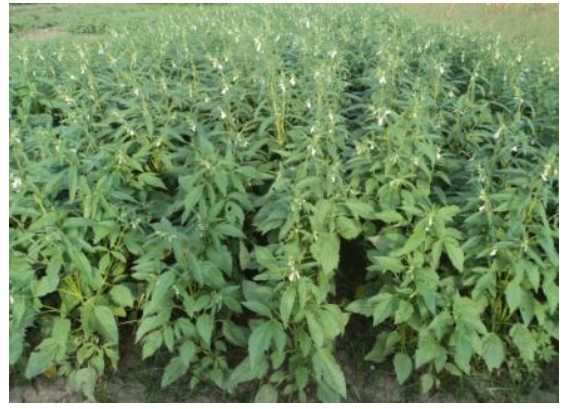

After 45 DAP/DAS of turmeric and sesame

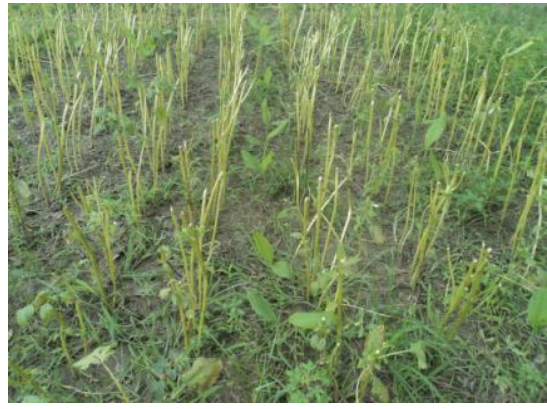

After harvest of sesame crop (95 DAP/DAS)

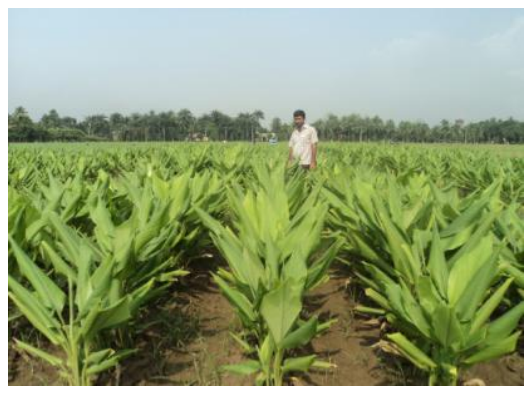

After 140 DAP of turmeric

Figure 1. Different stages of turmeric - sesame intercropping systems

\section{Turmeric equivalent yield (BEY)}

Turmeric equivalent yield gave higher (19.89-26.05 $\left.\mathrm{t} \mathrm{ha}^{-1}\right)$ in all the intercropping system over sole crop of turmeric $\left(18.00 \mathrm{t} \mathrm{ha}^{-1}\right)$. It's indicated that higher biomass production and consequently more efficient use of land and available resources under intercropping than under sole cropping. The highest turmeric equivalent yield $\left(26.05 \mathrm{t} \mathrm{ha}^{-1}\right)$ was found with turmeric $(100 \%)+3$ row sesame $(100 \%)$ in between turmeric lines intercropping system. 
M. R. Islam et al.

\section{LER, RVI and MAI of turmeric-sesame intercrop}

The land equivalent ratio exceeded unity in most intercropping systems in the experiments indicating an advantage of intercropping compared to the sole cropping (Table 4). However, the highest LER (2.28) was obtained in turmeric $(100 \%)+3$ row sesame $(100 \%)$ in between turmeric lines intercropping system. This means that $128 \%$ of the yield of turmeric and sesame on intercrops is monocrops.

Replacement value of intercropping (RVI) is one of a better measure of economic advantage of intercropping. The maximum value (2.34) of RVI was observed in turmeric $(100 \%)+3$ row sesame $(100 \%)$ in between turmeric lines intercropping system. This implies that the farmers practice intercropping of turmeric $(100 \%)+3$ row sesame $(100 \%)$ in between turmeric lines will be making $134 \%$ more profit than the farmers who are involved in turmeric and sesame monocropping.

The monetary advantage index (MAI) also gives an indication of the economic advantage of the intercropping system. The values of MAI were positive in all the intercropping system. The result revealed that yield and economic advantages in turmeric-sesame intercropping at all the combination were over their sole cropping. The highest MAI (Tk. $294953 \mathrm{ha}^{-1}$ ) was obtained in the turmeric $(100 \%)+3$ row sesame $(100 \%)$ in between turmeric lines intercropping system, which implied that the planting pattern was highly economical and advantageous for the mixtures. Dhima et al. (2007) reported that if LER and relative crowding coefficient (K) values were higher, there was an economic benefit expressed with MAI values such as obtained in the present study.

\section{Competitive ratio (CR)}

Competitive ratio values showed variation among the intercropping indicating differential competitive ability of component crop as influenced by intercrops of sesame at different populations (Table 5). Turmeric showed higher value of CR (1.34-2.22) than the sesame (0.45-0.75) in all intercropping combination indicating turmeric as the best competitor than sesame. Turmeric exhibited better competitive ability in all the combination probably turmeric plant was highly responsive to intercrops of sesame. Lower values of difference in CR indicated similarities of competitiveness but higher values of difference in CR indicated more dissimilarities of competitiveness between the species grown in mixture. Consequently, turmeric $100 \%+1$ line sesame (33\%) in between two turmeric lines intercropping system with higher difference of CR (1.77) exhibited dissimilarities competitiveness between the component crops (Table 5). However, turmeric 100\% +3 line sesame $(100 \%)$ in between two turmeric lines intercropping system with lower CR (0.60) showed merely similar competitiveness between the component crops. The results expressed that similar competitiveness with minimum CR between component crops provided complementary utilization of growth resources for better performance of intercropping with higher productivity. The results are in agreement with the finding of Nyakatawa, (1998) and Islam, (2002). The CR over 1 (unity) indicates the species 
as good competitor while less than 1 (unity) indicates the species as poor competitor when grown in association (Jedel et al., 1998).

\section{Economic return of turmeric-sesame intercropping system}

On the basis of mean of 2 years, the highest monetary return was observed in turmeric $(100 \%)+3$ row sesame $(100 \%)$ in between turmeric lines intercropping system which gave an additional income of Tk.149299 over the sole crop of turmeric. All the intercrop combination gave monetary advantages over turmeric alone.

Table 3: Economics of intercropping sesame with turmeric (average of two years)

\begin{tabular}{c|c|c|c|c|c}
\hline Treatments & $\begin{array}{c}\mathrm{TEY} \\
\left(\mathrm{t} \mathrm{ha}^{-1}\right)\end{array}$ & $\begin{array}{c}\text { Gross return } \\
\left(\mathrm{Tk} \mathrm{ha}^{-1}\right)\end{array}$ & $\begin{array}{c}\text { Total cost } \\
\left(\mathrm{Tk} \mathrm{ha}^{-1}\right)\end{array}$ & $\begin{array}{c}\text { Gross margin } \\
\left(\mathrm{Tk} \mathrm{ha}^{-1}\right)\end{array}$ & BCR \\
\hline $\mathrm{T}_{1}$ & 19.89 & 397700 & 145431 & 252269 & 2.73 \\
$\mathrm{~T}_{2}$ & 24.83 & 496550 & 147048 & 349502 & 3.38 \\
$\mathrm{~T}_{3}$ & 26.05 & 520900 & 148665 & 372235 & 3.50 \\
$\mathrm{~T}_{4}$ & 25.86 & 517100 & 149234 & 367866 & 3.47 \\
$\mathrm{~T}_{5}$ & 18.00 & 360000 & 137064 & 222936 & 2.63 \\
$\mathrm{~T}_{6}$ & 2.31 & 46200 & 37800 & 8400 & 1.22 \\
\hline
\end{tabular}

Market price:

Turmeric: TK 20/kg, Mungbean: Tk 60/kg and sesame: Tk 35/kg

Table 4. Land equivalent ratio (LER), replacement value of intercropping (RVI) and monetary advantage index (MAI) of sesame-turmeric intercropping system (average of two years)

\begin{tabular}{c|cc|c|c|c}
\hline \multirow{2}{*}{ Treatments } & \multicolumn{3}{|c|}{ LER values } & \multirow{2}{*}{ RVI } & \multirow{2}{*}{ MAI (Tk. ha $\left.{ }^{-1}\right)$} \\
\cline { 2 - 4 } & Turmeric & Sesame & Total & & \\
\hline $\mathrm{T}_{1}$ & 1.04 & 0.47 & 1.51 & 1.78 & 135042.90 \\
$\mathrm{~T}_{2}$ & 1.27 & 0.86 & 2.13 & 2.23 & 262934.94 \\
$\mathrm{~T}_{3}$ & 1.32 & 0.96 & 2.28 & 2.34 & 294952.62 \\
$\mathrm{~T}_{4}$ & 1.32 & 0.92 & 2.24 & 2.32 & 286459.79 \\
$\mathrm{~T}_{5}$ & 1.00 & 0.00 & 1.00 & 1.61 & 0.00 \\
$\mathrm{~T}_{6}$ & 0.00 & 1.00 & 1.00 & 0.21 & 0.00 \\
\hline
\end{tabular}




\section{Aggressivity, relative crowding coefficient and SPI of turmeric-sesame intercrop}

Aggressivity (A), relative crowding coefficient and system productivity index (SPI) of turmeric-sesame intercropping system are presented in table 6. The value of aggressivity determines the competitive ability of the component crops in an intercropping system. In different intercropping system, there was a positive sign for turmeric and a negative sign for the intercropped sesame indicating that turmeric was dominant while sesame was dominated. Data showed positive aggressivity for turmeric at turmeric $100 \%+3$ lines sesame $(100 \%)$ in between two turmeric lines and turmeric $100 \%+$ sesame broadcast $(100 \%)$ in between two turmeric lines intercropping system while its proved less competitive and was dominated by sesame at turmeric $100 \%+1$ line sesame $(33 \%)$ in between two turmeric lines and turmeric $100 \%+2$ lines sesame $(67 \%)$ in between two turmeric lines intercropping system. Intercropping of 2 lines sesame $(67 \%)$ in between two turmeric lines (100\%) showed minimum competitive ability between the component crops.

Relative crowding coefficient of turmeric and sesame was more than 1 indicating greater non-competitive interference than the competitive one (Table 6). The intercropped sesame had higher relative crowding coefficient values than the intercropped turmeric. Negative relative crowding coefficient values for turmeric were obtained in all intercropping system (Table 6). Intercropping of turmeric 100\% +3 lines sesame $(100 \%)$ in between two turmeric lines had highest relative crowding coefficient compared to other intercropping system.

Table 5. Competitive ratio (CR) of turmeric and sesame

\begin{tabular}{c|c|c|c}
\hline Treatments & $\begin{array}{c}\text { competitive ratio of } \\
\text { turmeric }\end{array}$ & $\begin{array}{c}\text { competitive ratio of } \\
\text { sesame }\end{array}$ & Difference \\
\hline $\mathrm{T}_{1}$ & 2.22 & 0.45 & 1.77 \\
$\mathrm{~T}_{2}$ & 1.48 & 0.67 & 0.81 \\
$\mathrm{~T}_{3}$ & 1.34 & 0.75 & 0.60 \\
$\mathrm{~T}_{4}$ & 1.43 & 0.70 & 0.72 \\
$\mathrm{~T}_{5}$ & - & - & - \\
$\mathrm{T}_{6}$ & - & - & - \\
\hline
\end{tabular}

$\mathrm{T}_{1}=$ Turmeric $100 \%+1$ line sesame $(33 \%)$ in between two turmeric lines, $\mathrm{T}_{2}=$ Turmeric $100 \%+2$ lines sesame $(67 \%)$ in between two turmeric lines, $\mathrm{T}_{3}=$ Turmeric $100 \%+3$ lines sesame $(100 \%)$ in between two turmeric lines, $\mathrm{T}_{4}=$ Turmeric $100 \%+$ sesame broadcast $(100 \%)$ in between two turmeric lines, $\mathrm{T}_{5}=$ Sole Turmeric and $\mathrm{T}_{6}=$ Sole sesame 
Table 6. Aggressivity, crowding coefficient, system productivity index of turmeric and sesame

\begin{tabular}{|c|c|c|c|c|c|c|}
\hline \multirow[t]{2}{*}{ Treatments } & \multicolumn{2}{|c|}{ Aggressivity } & \multicolumn{2}{|c|}{ Relative crowding coefficient } & \multirow{2}{*}{$\begin{array}{c}\text { Relative } \\
\text { crowding } \\
\text { coefficient } \\
(\mathrm{K})\end{array}$} & \multirow{2}{*}{$\begin{array}{c}\text { System } \\
\text { productivity } \\
\text { index (SPI) }\end{array}$} \\
\hline & Turmeric & Sesame & $\begin{array}{c}\text { Turmeric } \\
\text { (Kab) }\end{array}$ & $\begin{array}{l}\text { Sesame } \\
(\mathrm{Kba})\end{array}$ & & \\
\hline $\mathrm{T}_{1}$ & -0.37 & 0.37 & -7.76 & 2.69 & 20.87 & 27.25 \\
\hline $\mathrm{T}_{2}$ & -0.01 & 0.01 & -3.16 & 8.89 & 28.09 & 38.25 \\
\hline $\mathrm{T}_{3}$ & 0.36 & -0.36 & -4.12 & 25.40 & 104.65 & 41.09 \\
\hline $\mathrm{T}_{4}$ & 0.40 & -0.40 & -4.15 & 12.20 & 50.63 & 40.36 \\
\hline $\mathrm{T}_{5}$ & - & - & - & - & - & - \\
\hline $\mathrm{T}_{6}$ & - & - & - & - & - & - \\
\hline
\end{tabular}

$\mathrm{T}_{1}=$ Turmeric $100 \%+1$ line sesame $(33 \%)$ in between two turmeric lines, $\mathrm{T}_{2}=$ Turmeric $100 \%+2$ lines sesame $(67 \%)$ in between two turmeric lines, $\mathrm{T}_{3}=$ Turmeric $100 \%+3$ lines sesame $(100 \%)$ in between two turmeric lines, $\mathrm{T}_{4}=$ Turmeric $100 \%+$ sesame broadcast $(100 \%)$ in between two turmeric lines, $\mathrm{T}_{5}=$ Sole Turmeric and $\mathrm{T}_{6}=$ Sole sesame

The system productivity index (SPI) which standardized the yield of the secondary crop in terms of the primary crop and also identified the combinations that utilized the growth resources most effectively and maintained a stable yield performance (Tajudeen, 2010). The results showed that the turmeric 100\% + 3 lines sesame $(100 \%)$ in between two turmeric lines intercropping system gave the highest value (41.09) than the other intercropping system. The values of SPI were higher and largely determined by turmeric intercrop yields which were not much reduced by intercropping with sesame.

\section{CONCLUSION}

Now a day, farmers are not interested to grow long durated crops. In these intercropping system farmers could be attracted to cultivate long durated turmeric crop to getting maximum profit. Beside, majority farmers of Bangladesh have certain land area which is not enough to meet up the annual food security. This intercrops cultivation they could be increase their productivity in unit land area. It will be helps to increase sesame cultivated area where scarcity of oil demand is common phenomena in our country. It was also revealed that intercropping sesame with turmeric enhances turmeric growth and development resulted better rhizome yield. The data indicating that intercropping sesame with turmeric gave maximum productivity as well as economic returns than sole crop of components crops. However, for better productivity and economic advantages of turmeric-sesame 
M. R. Islam et al.

intercrop combinations, a planting pattern comprising of turmeric $100 \%+3$ lines sesame $(100 \%)$ in between two turmeric lines intercropping system should be adopted to get maximum return.

\section{REFERENCES}

AIS (Agricultural Information Service). 2015. Krishi Diary (Agricultural Diary). Agril. Infor. Service, Khamarbari, Farmgate, Dhaka 1215. pp.75-76

Ali, M. and Mishra, J. S. 1993. Intercropping of blackgram (Phaseolus mungo) and greengram ( $P$. radiatus) with spring sunflower (Helianthus annuus). Indian Journal of Agricultural Sciences, 63(8):493-495

BSA (Bangladesh Society of Agronomy). 2013. Souvenir. "12 $2^{\text {th }}$ Conference on Agronomic Research for Enhancing Sustainable Crop Production." held on 20 September, 2013 in Bangladesh Agricultural Research Council (BARC), Farmgate, Dhaka. p.27

Ghosh, P. K. 2004. Growth, yield, competition and economics of groundnut/cereal fodder intercropping systems in the semi-arid tropics of India. Field Crops Research 88, 227237

Haque, M. M. and Hossain, S. M. M. 1985. Spice and root crops in the context of homestead garden in Bangladesh. Workshop proceedings, present status and future prospects of research on root and spice crops. BARC, $\mathrm{p} 51$

Joyachandran, B. K., bari, M. M., Salam, M. A., mannan, M. K. and Mathew, K. P. 1991. Performance of turmeric/ginger under shade and open condition. Indian Coca, Arecanut and Spices Journal, XV (2): 40-42

Jedel, P. E., Helm, J. H. and Burnett, P. A. 1998. Yield, quality and stress tolerance of barley mixture in central Alberta. Canadian Journal of Plant Sciences, 78:429-436

Ullah, M. A., Wahab, M. A. and Mondal, M. R. I. 2001. Importance and uses of plants oil (In Bangla). Oilseed Research Centre, BARI, Joydebpur, Gazipur. 15P.

MOA (Ministry of Agriculture). 2014. Hand Book of Agricultural Statistics, December 2007. Government of the Peoples Republic of Bangladesh. http://www.moa.gov.bd/statistics/ statistics.htm

Mosely, W. G. 1994. An equation for the replacement value of agroforestry. Agroforestry system, 26:47-52

Odo, P. E. 1991. Evaluating short and tall sorghum varieties in mixtures with cowpea in Sudan Savanna of Nigeria: LER, grain yield and system productivity index. Experimental Agriculture, 27, 435-441

Tajudeen Olusegun Osen. 2010. Evaluation of sorghum-cowpea intercrop productivity in savanna agro-ecology using competition indices. Journal of Agricultural Sciences, 2(3):229-234

Willey, R. W. and Rao, R. M. 1980. A competitive ratio for quantifying competition between intercropping. Experimental Agriculture, 16 (1): 17-125 